\title{
MULTINATIONAL EXPANSION OF WORKER COOPERATIVES AND THEIR EMPLOYMENT PRACTICES: MARKETS, INSTITUTIONS, AND POLITICS IN MONDRAGON
}

\author{
IGNACIO BRETOS, ANJEL ERRASTI, AND CARMEN MARCUELLO*
}

\begin{abstract}
Drawing on qualitative research and longitudinal data on two Mondragon multinational cooperatives, the authors examine the multinational expansion of these co-ops and the diffusion of the cooperative model's employment practices to their subsidiaries in Brazil, China, Slovakia, France, and Poland. The results show that international expansion can radically transform the organizational architecture of co-ops and exacerbate dilemmas about how to put their hallmark values into practice. Moreover, the findings reveal a fragmented and inconsistent introduction of the cooperative model overseas. Work organization practices are homogeneous across the various sites, whereas job security, training, and pay equity practices are not. Core cooperative practices (i.e., employee participation in ownership, profit sharing, and general management) have not been implemented in any foreign operation. The study illustrates how market influences, institutions, and macro- and micro-politics shape the transfer of employment practices.
\end{abstract}

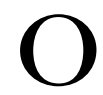

ver the past two decades or so, an increasing range of organizations that are not simply capitalist firms driven by shareholder value, such as state-owned enterprises, firms controlled by sovereign wealth funds,

\footnotetext{
*Ignacio Bretos ( (D) https://orcid.org/0000-0002-4941-2028) is a Researcher at the Caja Rural de Teruel Chair of Cooperatives and Social Economy, University of Zaragoza. Anjel ERRASTI is a Professor at the Institute of Cooperative Law and Social Economy, University of the Basque Country. CARMEN MarCuello is a Professor at the University of Zaragoza.

The authors would like to express their gratitude to Carmen Fernández, Patricia Ares, Tom Webb, Virginie Pérotin, Ana Paula Carletto Mondadore, Dave Passingham, Clare Abraham, and all the interviewees for their contribution to this research. Many thanks also to the participants in the 18th conference of the International Association for the Economics of Participation for their comments on an earlier draft of this paper. The authors acknowledge financial support from the Programa Operativo Feder Aragón 2014-2020, as well as from the research institutions GEZKI (Institute of Cooperative Law and Social Economy) and HEGOA (Institute for International Cooperation and Development Studies) attached to the University of the Basque Country. For further information regarding the data and/or computer programs utilized for this study, please contact the authors at ibretos@unizar.es.
}

KEYWORDs: cooperatives, multinational corporations, employment relations, human resource management, internationalization, Mondragon

ILR Review, XX(X), Month 201X, pp. 1-26 DOI: 10.1177/0019793918779575. (C) The Author(s) 2018

Journal website: journals.sagepub.com/home/ilr

Reprints and permissions: sagepub.com/journalsPermissions.nav 
family-owned businesses, and nonprofits, have been expanding beyond their traditional national boundaries (e.g., Chen, Saarenketo, and Puumalainen 2017). A prominent example is the case of worker cooperatives (WCs), which are usually portrayed as small locally owned and democratically managed firms, and regarded as the highest expression of participation from employees because they contribute both labor and capital (Cheney, Santa Cruz, Peredo, and Nazareno 2014). Globalization pressures, however, have compelled many WCs to turn into multinational companies (MNCs) to maintain their competitiveness (McMurtry and Reed 2009). In the absence of statistics on the percentage of overall foreign direct investment that is accounted for by cooperatives, recent reports by the International Co-operative Alliance on the economic weight of the 300 largest co-ops in the world (see ICA 2016) demonstrate that the international expansion of cooperatives is a far from marginal phenomenon. Approximately $90 \%$ of those 300 co-ops operate across borders (Bretos, Díaz-Foncea, and Marcuello 2018).

In light of this, several scholars have called for an exploration of WC internationalization and of the possibilities of reproducing the cooperative model in subsidiaries (e.g., Bretos and Marcuello 2017; Cheney et al. 2014). Accordingly, two research questions guide this study: 1) How do WCs conduct the multinational expansion process and how does this affect their organizational architecture? 2) What tensions surround the transfer of the cooperative model to foreign subsidiaries? To address these questions, we provide a qualitative study of Fagor Electrodomesticos and Fagor Ederlan, two multinational WCs belonging to the Mondragon Cooperative Corporation (henceforth MCC). In accounting for transfer of the cooperative model, we focus on the core practices that distinguish WCs, that is, worker participation in ownership, profit sharing, and general management (i.e., worker involvement in decision making at the strategic management level). We also investigate other human resource (HR) practices inherent to WCs, including job security, extended training, teamwork, information sharing, and pay equity (Lertxundi 2011).

We contribute to the literature in three directions. First, whereas the scant previous research on multinational co-ops has generally adopted a paternalistic lens, both overlooking the contradictions raised by internationalization and explaining extension of the cooperative model merely in institutionalist terms, our research provides a more detailed and critical picture that also draws attention to the role of power and interests within these organizations. Second, our analysis of co-op multinational expansion addresses recent appeals in international business (IB) research to explore the internationalization of alternative organizations (Chen et al. 2017), contributing as well to a growing strand of inquiry on the challenges that market globalization entails for WCs to maintain their cooperative practices while remaining economically efficient (e.g., Atzeni 2012). Last, by examining the transfer of HR practices within multinational co-ops, we contribute to broadening the horizons of international human resource management 
(IHRM) beyond the hitherto exclusive consideration of shareholder-owned MNCs (Delbridge, Hauptmeier, and Sengupta 2011). Drawing on insights from market-based, institutionalist, and political perspectives on practice transfer (Edwards, Colling, and Ferner 2007), our research uncovers distinctive patterns in the management of labor and diffusion of employment practices within cooperatives.

\section{Theoretical Framework and Literature Review}

The IB literature contends that internationalization has become an indispensable strategy for firms to stay competitive in markets, especially in situations of economic crisis (Lee and Makhija 2009). A variety of works have analyzed internationalization strategies pursued by firms, foregrounding offshoring and offshore outsourcing among those of most importance (Feenstra 2010). Whereas offshoring implies that firms relocate their business functions to overseas locations by setting up their own centers or subsidiaries, offshore outsourcing refers to the subcontracting of foreign providers for specific activities (Kedia and Mukherjee 2009). The consequences of these practices have led to a heated debate. Some scholars contend that they create value for companies and for the economy as a whole (Farrell 2005). Other studies, however, demonstrate that jobs in low-income affiliates are substitutes for domestic jobs, whereas jobs in high-income affiliates are complementary (Harrison, McMillan, and Null 2007). And other researchers argue that offshoring generates gains in terms of wages and employment for high-skilled workers at the expense of middle- and lowskilled workers (Oldenski 2014).

In view of this debate, some critical scholars in the field of IB studies have emphasized that we must further our knowledge of internationalization strategies pursued by alternative organizations and determine whether such strategies offer sustainable alternatives that consider the rights and interests of workers (e.g., Roberts and Dörrenbächer 2016; Chen et al. 2017). WCs have attracted some attention because these organizations are expected to pursue the mutual benefits of the diverse stakeholders involved in crossborder activity (Zanfei 2012). As WCs are owned and governed by workers who are intrinsically linked to the local territory, the choice of how they internationalize is likely to be shaped by other aspects beyond purely economic decisions, such as the involvement of labor in management and the social embeddedness of actors (Schröder 2013). Likewise, the literature holds that WCs are expected to establish their subsidiaries as co-ops or, at least, seek to organize abroad in an alternative way to capitalist MNCs (Flecha and Ngai 2014). In fact, it is widely argued that the setting-up of capitalist subsidiaries may involve drastic contradictions with the practices and values of WCs, although little is known about how such contradictions are constituted and how they are legitimized or contested by the diverse organizational actors (Kasmir 2016). 
According to the IB literature, the factors shaping the internationalization strategy will also influence the $\mathrm{MNC}$ organizational architecture (Jensen, Larsen, and Pedersen 2013). A number of models have been proposed to depict the balance between central control and subsidiary autonomy within MNCs (Bartlett and Ghoshal 1998). Three basic alternatives can be distinguished: the "global" MNC, in which the headquarters (HQ) exerts strong centralized control (Ferner et al. 2013); the "multi-domestic" MNC, in which subsidiaries feature notable autonomy within a decentralized federation (Andersson, Forsgren, and Holm 2007); and the "transnational" MNC, which attempts to secure benefits from both centralization and decentralization (Bartlett and Ghoshal 1998). The prior literature suggests that the organizational architecture of multinational WCs is likely to resemble federative models because of their actors' social embeddedness, alignment with local community interests, and, keeping in line with the principles of autonomy and self-management, activities and processes are controlled by those directly involved in them (McMurtry and Reed 2009; Bretos and Marcuello 2017). Other pressures may lead WCs to lean on some centralization though. A key aspect is that worker-members will logically look to protect their job and investments in the co-op, and thus, endowing subsidiaries with total autonomy may jeopardize worker-members' control over the capital they have invested and job stability at the HQ.

Moreover, within any given architecture, a key issue lies in the nature and scope of the transfer of HR practices across the multinational network. Although diffusion within global MNCs tends to take place from the HQ to subsidiaries, transnational solutions may result in considerable multidirectional transfer. Conversely, transfer is prone to be lower in multi-domestic MNCs, because of the tendency to adopt local practices (Björkman and Lervik 2007). The cross-national transfer of practices in MNCs has been addressed from three broad theoretical perspectives: market-based, institutionalist, and political (Edwards et al. 2007).

The market-based view is that firms confront strong competitive pressures from product, financial, and labor markets and, to obtain international competitive advantages, they seek innovative best practices, which they then try to implement in their foreign operations (Taylor, Beechler, and Napier 1996). Emulation of global best practices is prone to occur when MNCs that stem from subordinate national business systems (NBSs), and that are deficient in specialized managerial competencies, mimic best practices originating in hegemonic NBSs (Geary and Aguzzoli 2016). The second perspective focuses on the influence of institutions in transfer, usually resorting to neoinstitutionalist theory. A crucial concept is institutional distance, which refers to the nature of institutional differences at the regulatory (existing laws and formal rules), normative (values, beliefs, and norms held by individuals), and cognitive (individuals' shared perceptions of reality) levels between the MNC's country of origin and the subsidiary's country of operation (Kostova 1999). A greater institutional distance will involve a greater host country 
effect, which implies that the subsidiary's labor practices will be shaped by local isomorphic pulls. Conversely, the shorter the institutional distance, the greater will be the country-of-origin effect (Quintanilla, Susaeta, and Sánchez-Mangas 2008). Last, the political perspective depicts the MNC as a contested terrain in which actors look to protect or further their own interests (Edwards and Bélanger 2009). The literature suggests that if subsidiaries have power resources stemming from their local embeddedness, they will be better positioned to resist or negotiate transfer. In addition, the HQ also has resources to overcome institutional hurdles within the host country and mechanisms to exert centralized control over subsidiaries, thus being able to transfer practices at discretion (Ferner, Edwards, and Tempel 2012).

Prior research posits that WCs will draw on local rather than on overseas practices, since they are usually integrated in local networks and seize on communitarian social capital and native knowledge (Borzaga and Sforzi 2014). This response is especially likely to occur when co-ops are closely linked to locally rooted consultancy firms and academic institutions (Leca, Gond, and Cruz 2014) and when there are training structures oriented to develop competent managers socialized in the cooperative culture, as is the case of MCC (Basterretxea and Albizu 2011). Nevertheless, one could also argue that WCs operating in highly competitive, globalized markets may be compelled to import prevailing global practices and systems and enforce them in their subsidiaries to promote productivity and economic performance. Institutional differences are expected to have special influence on practice transfer. A multitude of legal and cultural approaches to WCs occur worldwide (Borzaga and Spear 2004). Likewise, WCs are embedded in unique values and practices patterned on their respective local institutional contexts (Lertxundi 2011). Both aspects may involve divergent interpretations of cooperative practices among different regions, hence complicating diffusion. Indeed, industrial relations practices and, more specifically, employee participation have been found to be particularly sensitive to a host-country's institutional profile (Meardi et al. 2009). Last, issues of power and politics are likely to be relatively influential. The extant theory suggests that WCs may embody a more harmonious terrain in which power resources are scattered among international units and practice transfer is aligned with the interests of the internal stakeholders located across the multinational network-stakeholders who are expected to share similar values and establish the co-op's policies on a consensual basis (Zanfei 2012). That notwithstanding, it is equally evident that power imbalances and conflicting interests are prone to emerge if employees at subsidiaries do not become worker-owners.

Empirical evidence on the aforementioned aspects in WCs is extremely limited, although MCC represents one of the few exceptions. In general, the MCC multi-localization model-in which new business activities are opened abroad while maintaining production at home-is portrayed idyllically as an alternative to dominant delocalization trends (MacLeod and 
Reed 2009), given that Mondragon global co-ops have created more employment in the Basque Country than those that have stayed local (Luzarraga and Irizar 2012). As remarked by Kasmir (2016), however, these studies tell only one side of the story, ignoring the labor situation in international subsidiaries. Only a few studies have placed more emphasis on governance and employment relations issues in MCG's overseas plants, concluding that not a trace of the cooperative model can be found in them (Clamp 2000; Errasti 2015). Yet these studies are silent as to why the parent organizations do not reproduce the cooperative model abroad. By contrast, Luzarraga (2008) and Flecha and Ngai (2014) looked at Mondragon global co-op strategies for keeping cooperative values under international expansion and concluded that these co-ops have been able to extend the cooperative model overseas. Three main aspects can be criticized though: First, their argument is grounded in the partial implementation of some best practices in a handful of foreign plants, such as the enhancement of information mechanisms and employees' involvement in the work area. Second, the voices of the workforce at foreign plants are not included or are treated as passive actors. Third, they focus on some important barriers that hinder extension of the cooperative model overseas, such as legal constraints and cultural differences, but overlook the influence of power and interests.

Our empirical analysis addresses the transfer of the core practices that distinguish WCs, that is, employee share-ownership, profit sharing, and employee participation in general management (Cheney et al. 2014). We also examine other HR practices inherent to WCs and more specifically to the Basque cooperative model, including job security, direct employee participation in workplace-level decision making, extended training, and pay equity (Arando et al. 2011; Lertxundi 2011). In view of the above discussion, some degree of centralized control is likely to be found in WCs. Moreover, market pressures are expected to encourage diffusion of practices oriented to enhance efficiency in the subsidiaries, such as direct employee participation. Other high-commitment practices (job security, extended training, and pay equity) may also be the object of diffusion, while being shaped by market influences, institutions, and politics. Transfer of the core cooperative practices will arguably be constrained by institutional barriers and especially by issues of power and interests.

\section{The Mondragon Cooperative System and Case Studies}

A key feature upon which the Basque governance system is built is associationalism (Cooke, Uranga, and Etxebarria 1997), based on a long tradition of organizational democracy and workplace and community participation. The Mondragon cooperative system is probably the best embodiment of this institutional setting (see, e.g., Whyte and Whyte 1991). Founded about 60 years ago in the Mondragon valley, these cooperatives started out as small democratic organizations, with strong roots in the territory and a powerful 
sense of community. MCC has, however, undergone an extraordinary transformation. Globalization pressures have compelled many of its industrial cooperatives to internationalize since the early 1990s. The MCC's industrial heart consists of 30 multinational co-ops that control nearly 140 productive subsidiaries abroad, all of which are capitalist firms, and about 45 productive subsidiaries in Spain, 30 of which are non-cooperative firms (Mondragon 2017).

Despite this, cooperative values and practices still guide the functioning of Mondragon parent co-ops in the Basque Country. As owners, workermembers receive a share of profits and are involved in decision making in various ways. They participate in the General Assembly on a one-person/ one-vote basis and can be elected to the Governing Council and the Social Council (Arando, Gago, Jones, and Kato 2015). Workers also participate at the shop-floor level, although this involvement is promoted through mainstream management programs. With the aid of external consulting firms, in the 1980s and 1990s, MCC global co-ops imported prevailing models of total quality management (TQM) and lean production from the United States and Japan (Cheney 2005). Likewise, these co-ops imported the minicompany system in the early 2000 s, which, in a nutshell, is a way of structuring the organization so that each of its units operates as an autonomous company in which workers make decisions and solve problems at the shopfloor level. Moreover, internal promotion and job security are also paramount in Mondragon (Heras 2014). Dismissal of worker-members is extremely rare and, when a plant does occasionally close, they are relocated to other MCC co-ops. Although the bottom-top wage ratio has widened from $1: 3$ to $1: 8$ in some co-ops, it is evident that internal wage differences are still compressed. Only modest use has been made of performancerelated pay, even for top managers (Arando et al. 2011). Managers and worker-members receive extensive training not only in technical aspects but also in cooperative values and social skills, such as leadership and teamwork. Job security, training, and promotion opportunities are crucial to attract competent top managers, since such policies offset the comparatively low salaries for top managers in MCC co-ops (Basterretxea and Albizu 2011).

Meanwhile, a renewed debate about the future of the MCC experience, motivated by internal self-reflection and greater scholarly scrutiny and criticism, has led in recent years to a search for formulas to extend the cooperative model to the capitalist subsidiaries (Azkarraga, Cheney, and Udaondo 2012). Particularly after approval of the social expansion strategy (Flecha and Ngai 2014) at the 2003 MCC Cooperative Congress, many Mondragon co-ops have included the "cooperativization" (meaning diffusion of the cooperative model) of capitalist subsidiaries as a primary goal in their strategy plans. The aim of this goal is to directly transform the latter into WCs or, at least, implement the core cooperative practices that typify the Basque parent companies. Nevertheless, while some projects have been developed 
within the domestic field, advances registered in the case of foreign subsidiaries have been significantly more limited.

The household manufacturer Fagor Electrodomesticos and the automotive supplier Fagor Ederlan are prominent examples of these records. Before it entered into liquidation in October 2013, Electrodomesticos employed approximately 10,500 workers at 18 plants in Spain, France, China, Poland, Morocco, and Italy at its height in 2006. Ederlan, meanwhile, employed 3,600 workers at 16 plants in Spain, China, Brazil, and Slovakia in 2014 (see Table 1 for an overview). Both co-ops have developed cooperativization initiatives in the domestic field. The subsidiary Edesa was transformed into a WC in the late 1990s and was integrated as a plant belonging to the Electrodomesticos parent co-op. In 2004, the employees of the subsidiary Geyser-Gastech became worker-members of Electrodomesticos, although the company remained a subsidiary. Meanwhile, the subsidiary Fit Automoción became a cooperative plant of Ederlan in 2006. Victorio Luzuriaga Usurbil is currently undergoing the same process. And last, Fagor Ederlan Tafalla was transformed into a mixed cooperative ${ }^{1}$ in 2008 , and the employees became members of the new cooperative subsidiary.

\section{Data and Methods}

To address the questions raised earlier, we designed a qualitative empirical study on Ederlan and Electrodomesticos following the methodology of contemporary case studies (Yin 2013). We chose them because both have been cutting-edge co-ops in developing internationalization strategies and extending the cooperative model to their subsidiaries. Although Electrodomesticos went bankrupt in 2013 (see Errasti, Bretos, and Nunez 2017 for a detailed study of the co-op's closure), its analysis is useful to shed light on contemporary tensions surrounding the transfer of the cooperative model overseas.

In Fagor Electrodomesticos, the study focused on the cooperative $\mathrm{HQ}$ the Polish subsidiary Fagor Mastercook, and the French plants of the subsidiary Fagor Brandt. In Fagor Ederlan, we analyzed the cooperative HQ, the Chinese subsidiary Fagor Ederlan Auto-Parts Kunshan, the Brazilian subsidiary Fagor Ederlan Brasileira, and the Slovak subsidiary Fagor Ederlan Slovensko. We selected these foreign subsidiaries because they play different roles in their respective groups, and the countries where they are based represent varied institutional profiles, which offer a fairly broad picture to illustrate the factors influencing the transfer of employment practices. We also analyzed the Spanish subsidiary Fagor Ederlan Tafalla, located in Navarre, a region adjacent to the Basque Country, because its recent conversion into a

\footnotetext{
${ }^{1} \mathrm{~A}$ mixed cooperative is a formula found in some Spanish regions. It differs from a regular co-op as minority shareholders have voting rights at the general assembly based on their capital contributions.
} 


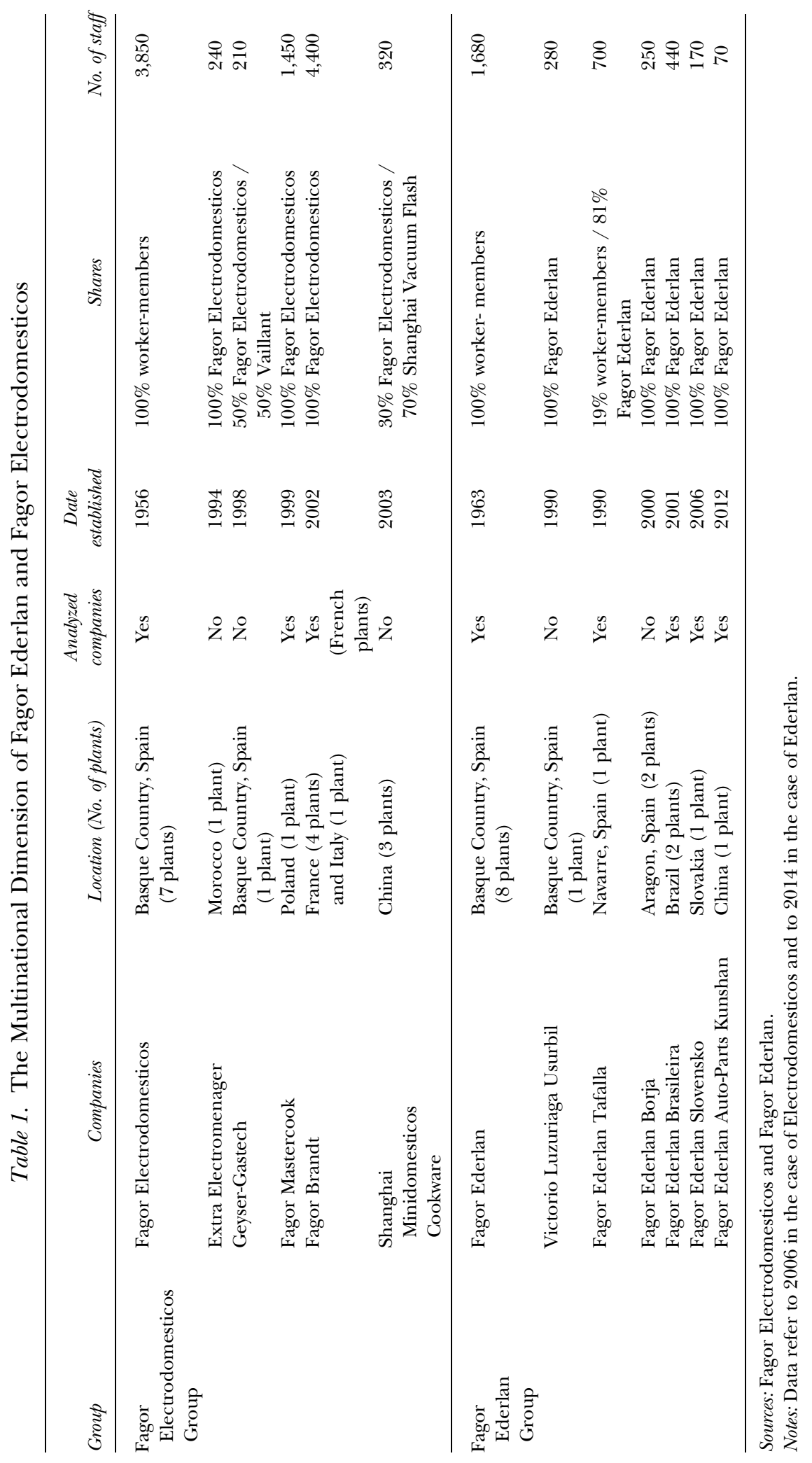


WC sheds light on the challenges involved in the cooperativization of foreign plants.

Data collection was based on various methods. First, we used archival methods to build a more contextualized and historically grounded case (Yin 2013). We consulted academic literature dealing with Mondragon, material gathered on the companies' webpages, in-house magazines, items from media archives, and published interviews. We also had access to a range of internal documentation furnished by both cooperatives and dating from the early 1990s onward (e.g., strategic plans and management plans, sustainability reports, and statutes). A total of 75 semi-structured interviews averaging 90 minutes each were conducted with worker-members, salaried and temporary workers, managers, union representatives, and representatives of the Governing Council and the Social Council. In Ederlan, we conducted 23 interviews between 2012 and 2015, including at the parent company (5), Fagor Ederlan Tafalla (7), Fagor Ederlan Auto-Parts Kunshan (7), and Fagor Ederlan Slovensko (4). Although we did not have the opportunity to visit Fagor Ederlan Brasileira, this subsidiary was extensively discussed in the interviews. In Electrodomesticos we carried out 52 interviews between 2005 and 2012 at the parent company (25), Fagor Mastercook (16), and the French plants of Fagor Brandt (11). The field study also drew on direct observation (Patton 2002). We visited all the plants accompanied by a person in charge (generally a senior manager from the HR department), touring the management offices and the shop floors. We were also allowed to attend some meetings of managers and expatriates.

Interviews with managers from HQs placed emphasis on the internationalization of these co-ops, the strategic role of each subsidiary, the dynamics of control/autonomy in HQ-subsidiary relations, and the extension of the cooperative model overseas. Interviews with the workers focused on governance and employment relations issues within the co-ops, and the challenges they perceived in the cooperativization of foreign subsidiaries. Meanwhile, the interviews at Tafalla mainly contrasted the views of managers, workers, and unions regarding the cooperativization of this plant and discussed the options for replicating this experience abroad. The interviews with managers of foreign subsidiaries dealt with the differences between HQs and subsidiaries in managing labor, autonomy, and policy discretion in relation with foreign plants; the role of managerial expatriates in introducing HQ's practices; the local response to transfer; and the possibilities of implementing the cooperative model. The key focus of the interviews with employees and union representatives at overseas plants was industrial relations and working conditions. We also raised questions about their social identity and sense of belonging to the company, views about the parent co-op and managerial expatriates, reactions to imposed practices, and willingness to work under the WC formula.

Interviews were primarily carried out in Spanish, Basque, English, and French, languages spoken by one or several of the authors, although Polish and Chinese were also used by a few of our respondents (in these cases we 
had the help of an English interpreter). We dismissed the option of translating the material into one single language at an early stage of the research because of the problems associated with misinterpretation and mistranslation, and the impossibility of achieving exact equivalence between different languages (Chidlow, Plakoyiannaki, and Welch 2014). Because of these conditions, we did not employ computer-aided software for analyzing the interview data. Instead, as proposed by Geary and Aguzzoli (2016), we conducted a qualitative form of content analysis. Given the scarce research in the area, content analysis was based on an inductive approach whereby patterns and categories are allowed to flow from the raw data rather than through application of theory-driven constructs (Patton 2002). This process was iterative and involved moving among data, emerging patterns, and the relevant literature until the data were distilled into adequate conceptual themes (Eisenhardt 1989). Three main themes emerged: the internationalization strategy and organizational architecture of Mondragon co-ops; the management of labor in subsidiaries; and the cooperativization of subsidiaries. Once this stage was completed, the key materials were translated into English and proofread by a native-speaker specialist.

\section{Key Research Findings}

\section{The Multi-Localization Strategy and Organizational Architecture of Mondragon Global Co-ops}

Mondragon WCs operating in highly globalized sectors have been pushed to internationalize since the mid-' 90 s in order to maintain their competitiveness and to safeguard jobs in the Basque plants. Mondragon co-ops back foreign direct investment, rather than seeking low labor costs overseas, primarily because of their need to follow their manufacturing clients abroad as suppliers, or simply to become large enough to compete. The distinguishing feature is that international expansion is rooted in the multi-localization strategy, which implies that the new business activity opened up abroad does not involve the closure of any pre-existing activity at home. Therefore, unlike the offshoring model practiced by many of their competitors, the MCC co-ops expand without closure of plants and job losses in the Basque Country. In the words of the Fagor Ederlan Group chairman:

\footnotetext{
Our competitors have offshored some assembly lines, chiefly to Eastern Europe and Asia, but this is not in our DNA. We are located in these regions as well, but we follow a multi-localization strategy aimed at maintaining and creating cooperative jobs here. In addition, when we locate in a place, it is for the long term and to generate employment, reinvest profits, and to promote local economic development there.
}

Equally, several cooperative members linked their social embeddedness in the region and rights in decision making with the maintenance of jobs. As an Electrodomesticos worker-member emphasized: 
In other companies, workers can't decide on their jobs. If the production is moved abroad and your plant is closed, the decision isn't up to you. It is even likely to be taken by a person who lives thousands of miles away. . . . Here [in the co-op], solidarity and local commitment are signs of identity. We all know each other; we live in surrounding villages, and it's us who make the decisions. So, nobody is going to vote for that. It would be like signing your own dismissal or that of your coworkers, relatives, and friends.

In general terms, multi-localization has furnished the MCC co-ops with extraordinary economic results, while favoring the creation of employment both in the Basque Country and abroad, and it has enabled them to cope satisfactorily with the recession. For instance, employment increased in the whole Fagor Ederlan Group from 1,312 workers in 1999 to almost 3,600 workers in 2014, and the number of workers in the parent co-op also rose from 1,452 to 1,641 between 2003 and 2008. ${ }^{2}$ This pattern was not so evident with Electrodomesticos. Although the multi-localization strategy helped the co-op weather the early recession years by counteracting the fall in domestic demand for appliances and high labor costs in Spain, before its collapse in 2013, only 5,500 workers remained in the group (just half of the total workforce in 2006). Of these, 1,900 were in the Basque Country.

Notwithstanding that outcome, Electrodomesticos and the Mondragon cooperative system have proved capable of dealing with this crisis situation with innovative, local job-sensitive solutions. For instance, instead of closing the Fagor-Brandt plants in Lyon (France) and Verolanuova (Italy) and making all the workers redundant, Electrodomesticos, in an agreement with the unions, transferred these plants to external business groups rather than sell them, thus saving most of the jobs. Even though the co-op did not retain a stake in these companies, it provided resources and know-how to help with the transition. As the HR director at Electrodomesticos said, "We prefer spending money in ways that enable jobs to be maintained before spending on compensation due to closure." Equally, today all the Electrodomesticos worker-members affected by its bankruptcy have been given a solution, primarily through early retirement and their relocation to other Mondragon co-ops.

Ederlan's HR director clearly depicted the philosophy underlying the commitment to local jobs as follows:

In Mondragon we only close plants when there is no choice, trying to save the jobs both at home and abroad. . . . If one co-op goes through difficulties, the others try to help. This is part of our philosophy. . . . We have designed a plan to absorb about 200 Electrodomesticos worker-members in our co-op. This is hardly conceivable in other conventional multinationals.

\footnotetext{
${ }^{2}$ This increase responds partly to the integration of the Basque subsidiary Fit Automoción as a cooperative plant of Ederlan in 2006, with the consequent incorporation of 90 employees as worker-members of the parent co-op.
} 
Nonetheless, the fundamental contradiction lies in the fact that foreign subsidiaries are established as capitalist firms. Therefore, unlike the cooperative members of the Basque parent companies, workers have no stakes in the firm's capital, profit distribution, election of the governing bodies, nor in its general management. In 2007 only 36\% were worker-members in the Fagor Ederlan Group, a similar percentage found in Fagor Electrodomesticos. These multinational cooperatives have, therefore, been transformed into what we might term "coopitalist" hybrids comprising a cooperative core (parent company) and a capitalist periphery (subsidiaries).

Regarding HQ-subsidiary relations, it is evident that the parent co-ops try to exert centralized control over foreign subsidiaries. First, they tend to retain the most technologically advanced processes and high value-added activities, such as product design, R\&D, and so on, at the Basque plants. A top manager at Ederlan admitted the prevalence of the parent's interests over those of foreign subsidiaries in the following terms:

The aim [of internationalization] is to maintain cooperative employment in the plants in the Basque Country, while we create employment and wealth abroad. Obviously, this means we will take strategic decisions with this in mind, thereby holding on to key resources and activities with the greatest added value in our plants.

Second, foreign subsidiaries have very restricted autonomy in strategic, technical, financial, and commercial aspects, which are areas usually managed by expatriates or managers very close to the parent. Comments such as "key decisions are made in the Basque Country" were ubiquitous among the subsidiaries' local workforce. This trend is also evident in the field of labor management, in which the policy discretion of foreign subsidiaries is generally constrained. Mondragon co-ops tend to combine the exercise of direct control by establishing HR policies in the subsidiaries with indirect mechanisms based on monitoring by way of expatriate personnel and communication between HQ and key managers in foreign plants.

\section{The Management of Labor in Mondragon's Foreign Subsidiaries}

Mondragon co-ops have implemented similar work organization practices and direct participation mechanisms at all the foreign subsidiaries. Variable pay schemes have also been introduced overseas, though these are decoupled from the Basque cooperative model. By contrast, there are marked differences as regards job security, training, internal promotion, pay equity, and collective employee voice. In sum, the bundle of practices associated with the cooperative model has been implemented overseas in a fragmented and inconsistent way, taking stronger root in some plants than in others.

Regardless of the host country, Ederlan and Electrodomesticos have implemented abroad the practices associated with production systems and work organization that resemble those of the Basque plants, thus suggesting 
a greater weight of market influences over institutional factors in this area of employment practice. To meet global market requirements in their respective sectors, both co-ops have replicated the same lean production techniques and mini-company system at all their plants. This upward problem-solving system entails considerable teamwork and horizontal communication. Production meetings between management and labor are held on a regular basis, so consultation and information sharing concerning production and technical aspects are prominent. In broader terms, suggestion systems exist for employees to voice their concerns. Ederlan and Electrodomesticos have also introduced variable pay schemes in all their subsidiaries, though these are not based on profit sharing or shareownership schemes, as is the case of the Basque co-ops, but rather on performance-related reward schemes that are characteristic of global best practices. Rewards are linked to productivity and quality for blue-collar workers and to periodically established objectives for senior managers. The introduction of these practices undoubtedly answers the need to attain some internal consistency among the dispersed multinational units, and achieve the goals of improved productivity through the implementation of variable pay schemes and managerially driven forms of participation that are exclusively focused on the workplace and assessed in terms of employee motivation and commitment to managerial objectives.

HQ managers also emphasized the interest of the co-ops in encouraging extensive training, internal promotion, job security, and pay equity abroad. Yet distinguishable patterns concerning introduction of these highcommitment practices are evident, influenced by the interplay of markets, institutions, and politics. First, differences according to international division of labor are prominent, which reflects a variation on market influences shaped by product- and labor-market contingencies. Fagor Ederlan Slovensko carries out production processes of a more labor-intensive and low value-added nature and operates with less-sophisticated technology, at least in comparison with other Ederlan units. This circumstance translates into a strategic HRM approach that focuses to a greater degree on tight work monitoring and cost minimization, placing weaker emphasis on training, pay equity, and job security. Some workers pointed out that training is scarce and takes place "on the job," and that the harsh management style translated into high work pressure, among other effects. Numerical flexibility in the form of temporary contracts is also more prominent in this plant, which contributes to a significant annual employee turnover that usually exceeds $25 \%$.

Although the Chinese and Brazilian subsidiaries play an important role in Ederlan's global value chain, marked differences concern the management of labor between both, which can be chiefly explained by variations on institutional distance. Considerable institutional distance is involved with the former; some institutional similarity is evident with the latter. Ederlan's Chinese subsidiary, set up as a greenfield project in Kunshan Industrial 
Park, is a mini replica of the parent's most technologically advanced site in the Basque Country. Consequently, the requirement for a stable and skilled workforce with specialist knowledge pressures Ederlan to encourage extensive training, job security, and employee involvement. Although the plant was opened recently, advances in such policies have been restricted to an elite group of local managers and workers. The high dynamism of the labor market in Kunshan was regarded at Ederlan HQ as a major challenge for promoting extended training, internal promotion, and pay equity. (Workers vote with their feet by job-hopping, and dismissal is extremely simple due to the limited labor protection and the absence of unions.) Likewise, several managers emphasized the obstacles to stimulating employee participation in this plant, caused by the lack of creative, participatory, and teamwork skills among workers in Kunshan, which seems to stem from the historically rooted hierarchical style of management in Chinese firms (Gamble 2003).

By contrast, Fagor Ederlan Brasileira stands out for integrating several practices closely related to the parent co-op's model. This subsidiary has introduced some of the social equity policies that characterize Ederlan: Careers are divided into six categories, and for each of them a salary scale is established and a series of labor training objectives are defined. Employees also enjoy social benefits that include health insurance, luncheon vouchers, and transport. Likewise, an egalitarian wage policy has been introduced, reducing the wage gap from 1:27 in 2005 (Luzarraga 2008) to the current 1:18. These and other labor conditions are reviewed on an annual basis under agreement with unions to keep them at levels higher than the local firms. Ederlan's internal promotion policies have also been implemented, which, in combination with extensive training in technical and social skills, has drastically curbed employee turnover. Ederlan managers attributed the progress made in the Brazilian subsidiary both to its location in a favorable institutional setting and to the fact that this is their longest-running foreign subsidiary. They put the focus on the willingness of the subsidiary's employees to participate in the company, as well as on their receptiveness to valuing social goals and creating egalitarian relationships based on personal closeness in the workplace, all of which are salient features of the Brazilian NBS (Mellahi, Frynas, and Collings 2016).

Meanwhile, labor relations in the Fagor Electrodomesticos Group were marked by the difficult financial situation that the co-op underwent from the early 2000s and the growing pressures in the appliance industry to compete on price. Hence, market influences urged Electrodomesticos to pursue a low-road approach to HRM in their subsidiaries, especially after the outbreak of the financial crisis in 2008, although this was modulated in each foreign subsidiary by variations relating to institutional factors and politics.

In the case of the French subsidiary Brandt, Electrodomesticos HQ tried to implement a hard adjustment policy aimed at enhancing economic performance by reducing labor costs from the very beginning. This included 
layoffs and wage cuts, the greater use of temporary jobs, lower training opportunities, and higher work pressure on the assembly line. Yet the local workforce showed notable resistance to these impositions by deploying power resources from the institutional context and their collective organization. The large size of the subsidiary, the highly regulated labor market in France (with a solid labor legislation that grants substantial bargaining power to unions), the long-standing union culture in Brandt, and its ability to exert pressure on public opinion and the French government were highlighted by HQ management as major hindrances to execution of the planned restructuring. Some salient examples are the various stoppages and strikes in protest against restructuration measures, and the $1.2 \%$ wage increase under collective agreement in the French plants in 2009, just at the time when the Basque worker-members reduced their salary by $8 \%$ to withstand the economic downturn. These signs of resistance did not, however, prevent restructuring. In practice, labor involvement in corporate decision making is relatively low in France, and unions have access to little effective information and monitoring rights (Goyer and Hancké 2005). As a Confédération Générale du Travail (CGT) delegate stressed, "restructuring was carried out behind our backs, ignoring workers' social and labor demands, amidst a continuous struggle to get information."

The Polish subsidiary Mastercook yields a more complex picture, with a first phase of restructuring under agreement with unions; a second phase in which some cooperative practices were introduced in line with the plant's new role within the division of labor (although transfer was shaped by institutions); and a third phase in which a new restructuring plan encountered greater local resistance. Overall, of the Electrodomesticos foreign plants, Mastercook advanced the most in the introduction of the cooperative model. A prominent example is the inclusion of two trade union representatives on the subsidiary's board of directors, which stands out as a unique experience in MCC in promoting representative participation overseas beyond legal requirements. Nevertheless, this circumstance also seems to respond to calculated reasoning at HQ. As the HR director pointed out, "We encountered a highly unproductive and bureaucratized plant ... and the presence of the union representatives aided the restructuring that was needed." Restructuring involved downsizing from 1,700 to 1,200 jobs between 1999 and 2003, along with a balancing of the proportion between blue-collar and white-collar workers. However, most workers had been reinstated by 2008 .

Parallel to the increasingly strategic role that Mastercook gained after 2003 by introducing production lines that were unprofitable in Spain, selfmanagement was encouraged through semi-autonomous work teams, training opportunities were promoted, wage differentials were restricted, and employee turnover was reduced. However, organizational change was to face subtle hindrances. With 45 years of a centralized economic system behind them, Polish employees tended to disapprove of changes by 
displaying silent resistance (Hurt and Hurt 2005). We observed this behavior in aspects such as high absenteeism and the fact that workers commonly recognized their lack of sense of belonging to the company. As an expatriate HR manager stressed, "It's impossible to introduce the exact same parent HRM model here," ascribing it to "the meaning of job stability is absolutely different; workers don't take responsibility for their job and the company." The financial crisis in 2008 opened a new phase of restructuring with layoffs, wage cuts, and harsh industrial disputes, amid intense micropolitical struggles. A critical event involved the call for strike action by the left-wing union Sierpen-80 to "protest the super-exploitation measures and demand a wage increase of €300," as a union leader claimed. The Electrodomesticos board response was a threat of shutdown, forcing the subsidiary to surrender. In the words of the same interviewee, "[HQ] management settled the dispute with the threat of relocating the plant to Ukraine or Russia."

\section{Cooperativization of Foreign Subsidiaries}

As we have seen, Mondragon global co-ops have implemented certain employment practices closely linked to the cooperative model in some foreign subsidiaries. Equally evident, however, is that no foreign subsidiary has been transformed into a WC or has introduced comprehensively the core cooperative practices (i.e., employee participation in ownership, profit sharing, and general management). Although institutions are an important part of the story in understanding why the core of the cooperative model is not transferred overseas, issues of power and politics seem to play a more critical role.

In the managerial technostructure of the MCC co-ops, allusions to institutional factors are ubiquitous. The principal barriers mentioned include that, in the destination country, either no legislation on WCs has been developed or the legislation in place bears no similarity to that of the Basque Country. Our respondents echoed this regulatory institutional distance; for instance, regarding the case of China, this country lacks legislation specifically covering WCs. At the same time, the possibility of creating a European Cooperative Society (ECS) has not been explored in any of the foreign plants located in Europe. Although this step suggests a plausible solution that would overcome the regulatory institutional distance that stands in the way of transforming the European subsidiaries into WCs, an Electrodomesticos manager simply regarded it as "unreal," arguing that "the current economic conditions are not adequate, nor are the social conditions in the plants," and that "there is no interest from the workers and unions in becoming a cooperative." The company unions in Poland and France claimed, however, that nobody had ever proposed creating an ECS.

The other pillar of the discourse employed by the managerial technostructure to illustrate the complexity in the cooperativization of overseas 
plants is the possible lack of a cooperative and participatory culture among workers in foreign subsidiaries, not to mention the constraints against overcoming this barrier, such as high turnover rates and the employees' lack of a sense of belonging to the company. This attitude is particularly visible in the case of the Chinese subsidiary, where workers showed difficulties in properly interpreting the core cooperative practices because of their unfamiliarity with participative decision making and share ownership schemes. Workers expressed their reluctance to work under a cooperative formula. In broader terms, a manager from Ederlan Tafalla had this to say when asked about the prospect of encouraging employee participation in ownership, general management, and profit sharing overseas:

\begin{abstract}
In many countries where we are located there is not a rooted cooperative culture. You can't make a copy-and-paste of our model. . . . [Setting up a co-op] is a long process that needs to follow some steps: promote workers' autonomy to make decisions, support their progressive access to ownership, and instill a corporate cooperative culture. . . . This implies huge work in training workers in these values and practices, and it's impossible to carry this out without a stable and committed workforce.
\end{abstract}

Parent co-ops' efforts to promote a more cooperativist culture in foreign subsidiaries seem rather limited though, even in sites involving a relatively less marked institutional distance. In this regard, local members in the European subsidiaries commonly highlighted the MCC co-ops' lack of interest in instilling cooperative-like organizational values and offering workers the opportunity to become cooperative members. For instance, with reference to the French subsidiary Brandt, a CGT trade union representative pointed out that "we didn't have any cooperative training and nobody talked to us about the Mondragon model; they just talked about productivity improvements."

The project whereby Ederlan studied the legal conversion of its Brazilian subsidiary into a cooperative is probably the best embodiment of how Mondragon co-ops have instrumentalized the role of institutional factors to legitimize the non-cooperativization of foreign plants. According to $\mathrm{HQ}$ management, the project never got off the ground because of legal impediments and cultural differences. As the Fagor Ederlan Group chairman explained:

In Brazil we analyzed the possibilities of transforming a plant into a mixed cooperative, but the differences between our cooperative legislations prevented us from going ahead with the project. . . . Moreover, co-ops are understood very differently [in Brazil]; I think they are perceived more negatively.

Yet, it is evident that the Brazilian business system, with well-developed legislation on WCs, and a strongly rooted cooperative culture in the southeastern region (Lemaitre 2013) where the subsidiary is located, offered supportive conditions for transforming this plant into a WC. According to some 
in-house studies, Brazilian employees showed substantial willingness to become a Mondragon co-op as well (Luzarraga 2008). Some interviewees who witnessed the project firsthand confirmed off the record that there were no insurmountable barriers to transformation of the subsidiary, and that the underlying reason was the impossibility of setting up a mixed cooperative - a formula whereby, in practice, the parent co-op preserves the majority of the stakes and retains decision-making power through its presence in the governing bodies of the subsidiary.

This example illustrates how diffusion in multinational co-ops is critically played out at the micro-political level, influenced by HQ-subsidiary power relations and by core organizational actors in the HQ looking to protect their own interests. The co-ops are reluctant to lose control over all their business groups by promoting worker participation in ownership and giving greater autonomy to the subsidiaries, as they think that might be detrimental for the viability of the Basque plants. An Ederlan manager explained:

If, say, the Chinese or Slovakian subsidiary became cooperatives and had full decision-making autonomy, no one can guarantee us that they will remain in the group [Fagor Ederlan], and this produces uncertainty about the viability and survival of our cooperative.

An Electrodomesticos worker-member put forward a related idea:

Taken to the extreme, the Fagor Brandt and Fagor Mastercook workers might be a majority and, for instance, decide to close the Mondragon plants.

Our fieldwork also found a perception among the managers and workermembers of the parent companies that workers at the foreign subsidiaries would not develop as strong an identity and commitment to cooperative values and the company as their own. This perspective seems to stem from the lack of relations, links, and trust between the parent company and foreign subsidiaries. A clear example of this disunity and lack of understanding is the absence of a European Works Council (EWC) through which workers in the European Union have a right to information and consultation regarding company decisions at the European level. As a union representative of a French Electrodomesticos plant complained:

The Fagor parent company has a clearly laissez-faire attitude. No EWC or similar body has been created to let workers participate in decisions about the company, or to encourage relations between the parent company and the subsidiary.

Ultimately, this perception generates uncertainty among managers and worker-members about the success of a hypothetical cooperativization arrangement in a foreign subsidiary, as it might put job security at risk in the Basque plants. This concern was pervasive in the interviews. An Ederlan worker-member described the picture like this: 
We have no contact with the workers in the foreign subsidiaries. In other plants that have been turned into WCs here, like the one at Tafalla, we did maintain a closer relationship. . . . I think it's difficult for a cooperativization project to be successful in a foreign subsidiary. You don't acquire cooperative values overnight. What's more, I don't think they [the workers in the foreign subsidiaries] are going to develop an identity and take on such a solid commitment to the company as ours is with Fagor Ederlan. At the end of the day, if the cooperativization of a foreign subsidiary is not successful, it affects us all.

\section{Discussion and Conclusion}

This article was motivated by calls to analyze the multinational expansion of WCs and the diffusion of the cooperative model to foreign subsidiaries (McMurtry and Reed 2009; Cheney et al. 2014; Bretos and Marcuello 2017). Regarding the first research question, our findings reveal that Mondragon co-ops internationalize as a defensive strategy to safeguard the local jobs of worker-members. Solidarity values and moral arguments among workers, their involvement in corporate decision making, and their local roots in the co-op's home region prevent offshoring and prompt more sustainable patterns of international expansion capable of protecting local jobs. Whereas much of the previous literature operates on the assumption that the decision about offshoring production depends exclusively on economic calculations (see Schröder 2013 for a detailed critique), our findings extend extant knowledge by demonstrating that rank-and-file participation in management and the social embeddedness of decision makers at the home location also shape the choice of how firms internationalize.

Unlike previous studies (MacLeod and Reed 2009; Luzarraga and Irizar 2012), this article highlights how internationalization can transform the organizational architecture of co-ops and intensify the pressures to drift away from their hallmark practices, thus adding new flesh to ongoing debates about the challenges that WCs face to maintain their economic viability under market globalization pressures while staying true to their cooperative values and practices (e.g., Atzeni 2012; Flecha and Ngai 2014; Heras 2014). Multinational expansion has transformed MCC co-ops into coopitalist hybrids composed of a cooperative HQ and a capitalist periphery (subsidiaries) in which cooperative membership rights are restricted for workers. It is evident that the interests of the Basque worker-members prevail over those of peripheral employees overseas in terms of jobs, the manufacturing of high value-added products, R\&D, and so on. Indeed, HQ-subsidiary relationships in MCC co-ops are far from the federative models expected to be found in multinational WCs, evoking instead the global typology of MNCs identified by Bartlett and Ghoshal (1998), in which the HQ attempts to centralize decision-making power and strategic capabilities.

Regarding the second research question, our findings show how this organizational architecture shapes the nature of transfer across the multinational network. MCC co-ops have transferred similar work organization 
practices and direct employee voice mechanisms to all their subsidiaries, with notable application of teamwork, information sharing, and labormanagement communication at the shop-floor level. Variable pay schemes have been introduced overseas, although these are dissociated from the home-region model. The co-ops have implemented certain practices closely linked to the cooperative model in some plants (including extensive training, job security, and pay equity) while, at the same time, pursuing a lowroad approach to HRM in others. Meanwhile, no foreign plant has been transformed into a WC, nor has it introduced the core cooperative practices (employee participation in ownership, profit sharing, and general management). Overall, these results have some parallels to those for Germanowned MNCs, which have been found to uphold their model of employee participation based on codetermination and extensive consultation in home-based operations while embracing abroad HR practices patterned on the individualistic cost-minimizing Anglo-Saxon approach, including the use of direct participation mechanisms and numerical flexibility (Ferner and Varul 2000; Meardi et al. 2009).

Our research deconstructs this pattern of transfer by drawing on insights from market-based, institutionalist, and political perspectives. Thus, this article is situated within a reduced set of studies that have provided finegrained evidence of how diffusion across borders is shaped by the interrelated influence of market pressures, the macro-political terrain of the MNC (the home and host countries' institutions, and the subsidiaries' background, pattern of industrial relations, mode of establishment, age, size, and place in the international division of labor), and micro-political relations grounded in the actors' interests and power resources (e.g., Edwards et al. 2007; Ferner et al. 2012; Geary and Aguzzoli 2016).

First, homogeneity in practices associated with production systems and work organization across different national divides is consistent with some studies showing that this area of employment practice is largely shaped by market influences rather than by institutions (e.g., Meardi et al. 2009). It seems that rather than drawing on local knowledge and practices, Mondragon co-ops have imported mainstream regimes of managerialism and productivity from hegemonic NBSs, in the form of prevailing models of total quality management TQM, lean production techniques, and semiautonomous work groups (Cheney 2005), which they are now trying to enforce in their foreign plants to meet the market pressures toward worldclass productivity and quality imposed in their sectors. The introduction of performance-related reward schemes worldwide appears to be influenced by the need to be competitive in pay terms in the international markets, since the pay policies that typify the Basque co-ops (with salaries for top managers that are usually below the average) may make it difficult to attract and retain competent managers abroad. This trend illustrates how remuneration is also prone to be informed by global best practices (Ferner and Varul 2000). 
Second, the marked differences on training and skill formation, internal promotion, job security, and pay equity are explained by variations in market influences, institutional distance, and power resources, whose relative weight depends on the context of each subsidiary. Comparison of the Slovak and Chinese subsidiaries reveals how the subsidiary's role within the international division of labor shapes the HRM orientation (Wilkinson et al. 2001). At the same time, comparison of the Brazilian and Chinese subsidiaries verifies that institutional distance plays a mediating role in transfer, as contended by neo-institutionalists (Kostova 1999). Moreover, the political terrain that pervades multinational co-ops, which has been found to diverge considerably from the harmonious terrain that extant theory would suggest, is also an important part of the story. There is evidence of subsidiaries' actors drawing on power resources from the macro-political settings in which they operate to resist HQ's impositions (Geary and Aguzzoli 2016), as the French subsidiary Brandt illustrates. Nevertheless, the co-ops play an important role in setting or influencing subsidiaries' employment policy by combining direct control with indirect control through expatriation.

Third, the non-transfer of the core cooperative practices is consistent with the fact that host-country effects are more visible on employee participation practices (Meardi et al. 2009), hence corroborating the expected role of institutions in shaping diffusion within co-ops. Yet our research argues for a more pronounced emphasis on issues of power and interests, as supported by the non-cooperativization of the Brazilian subsidiary despite suitable institutional conditions. The underlying reasons also bring to light a distinctive pattern in diffusion. As noted by Chiang, Lemański, and Birtch (2017), the previous literature has overlooked cases in which it is risky to share certain HR practices or may entail losses to the transferring unit. In this regard, our findings illustrate an uncommon coalition in MCC MNCs between HQ management and worker-members to avoid genuine cooperativization of the foreign plants, as they deem it detrimental for their control over the business group and risky for the viability of the co-op, thereby generating a dilemma for the ultimate objective of internationalization in Mondragon: keeping cooperative jobs at the Basque plants.

An important limitation of this exploratory study may lie in the generalizability of our findings. Future research might therefore investigate other patterns in the management of labor within multinational co-ops operating in different industries and national settings. Likewise, a more detailed analysis of how practices evolve at different stages of the transfer process, placing emphasis on how these are implemented, integrated, and internalized in the subsidiaries (Chiang et al. 2017), may shed further light on the challenges surrounding the diffusion of employment practices within multinational co-ops.

This article also suggests some practical implications to facilitate the extension of the cooperative model. First, cooperativization projects in foreign subsidiaries should adapt to their own institutional contexts and 
integrate within them the perspectives of the workers, since there are different legislative and cultural approaches to co-ops worldwide (Borzaga and Spear 2004). Then again, the setting up of WCs is a bottom-up process, so HQ can only supply the means to carry this out in foreign plants, not impose it. A crucial step is to move toward federative models that endow the subsidiaries with greater autonomy and decision-making power. This move should be accompanied by the strengthening of social capital through trust-based relationships between $\mathrm{HQ}$ and subsidiaries, which is essential to lubricate the transfer of employment practices within MNCs (Björkman and Lervik 2007). At the parent co-op, this can create a greater determination to transfer the cooperative model's core practices. Equally, the subsidiary's trust in the HQ enormously facilitates acceptance of the practices transferred (Kostova 1999). Last, cooperativization should be preceded by education and training in cooperative values and practices at foreign subsidiaries. Otherwise, the transfer could fail owing to a clash with the host country's cognitive institutions, as workers might have difficulties in correctly interpreting such practices.

\section{References}

Andersson, Ulf, Mats Forsgren, and Ulf Holm. 2007. Balancing subsidiary influence in the federative MNC: A business network view. Journal of International Business Studies 38(5): 802-18.

Arando, Saioa, Fred Freundlich, Monica Gago, Derek C. Jones, and Takao Kato. 2011. Assessing Mondragon: Stability and managed change in the face of globalization. In Edward J. Carberry (Ed.), Employee Ownership and Shared Capitalism, pp. 241-71. Ithaca, NY: Cornell University Press/ILR Press.

Arando, Saioa, Monica Gago, Derek C. Jones, and Takao Kato. 2015. Efficiency in employeeowned enterprises: An econometric case study of Mondragon. ILR Review 68(2): 398-425.

Atzeni, Maurizio (Ed.). 2012. Alternative Work Organizations. London: Palgrave Macmillan.

Azkarraga, Joseba, George Cheney, and Ainara Udaondo. 2012. Workers participation in a globalized market: Reflections on and from Mondragon. In Maurizio Atzeni (Ed.), Alternative Work Organizations, pp. 76-102. New York: Palgrave Macmillan.

Bartlett, Christopher, and Sumantra Ghoshal. 1998. Managing across Borders, 2nd edition. London: Hutchinson.

Basterretxea, Imanol, and Eneka Albizu. 2011. Management training as a source of perceived competitive advantage: The Mondragon Cooperative Group case. Economic and Industrial Democracy 32(2): 199-222.

Björkman, Ingmar, and Jon E. Lervik. 2007. Transferring HR practices within multinational corporations. Human Resource Management Journal 17(4): 320-35.

Borzaga, Carlo, and Jacopo Sforzi. 2014. Social capital, cooperatives and social enterprises. In Asimina Christoforou and John B. Davis (Eds.), Social Capital and Economics, pp. 193-214. London: Routledge.

Borzaga, Carlo, and Roger Spear. 2004. Trends and Challenges for Co-operatives and Social Enterprises in Developed and Transition Countries. Trento: Edizioni 31.

Bretos, Ignacio, and Carmen Marcuello. 2017. Revisiting globalization challenges and opportunities in the development of cooperatives. Annals of Public and Cooperative Economics 88(1): 47-73.

Bretos, Ignacio, Millán Díaz-Foncea, and Carmen Marcuello. 2018. Cooperativas e internacionalización: Un análisis de las 300 mayores cooperativas del mundo. CIRIEC-España, Revista de Economía Pública, Social y Cooperativa 92: 5-37. 
Chen, Jie, Sami Saarenketo, and Kaisu Puumalainen. 2017. The internationalization of socially oriented organizations. In Kevin Ibeh, Paz Estrella, Odile Janne, and Xiaming Liu (Eds.), Growth Frontiers in International Business, pp. 167-93. New York: Palgrave.

Cheney, George. 2005. Democracy at work within the market: Reconsidering the potential. In Vicki Smith (Ed.), Worker Participation, pp. 179-203. Amsterdam: Emerald.

Cheney, George, Iñaki Santa Cruz, Ana M. Peredo, and Elías Nazareno. 2014. Worker cooperatives as an organizational alternative: Challenges, achievements and promise in business governance and ownership. Organization 21(5): 591-603.

Chiang, Flora, Michal Lemański, and Thomas Birtch. 2017. The transfer and diffusion of HRM practices within MNCs: Lessons learned and future research directions. International Journal of Human Resource Management 28(1): 234-58.

Chidlow, Agnieszka, Emmanuella Plakoyiannaki, and Catherine Welch. 2014. Translation in cross-language international business research: Beyond equivalence. Journal of International Business Studies 45(5): 562-82.

Clamp, Christine. 2000. The internationalization of Mondragon. Annals of Public and Cooperative Economics 71 (4): 557-77.

Cooke, Philip, Mikel G. Uranga, and Goio Etxebarria. 1997. Regional innovation systems: Institutional and organisational dimensions. Research Policy 26: 475-91.

Delbridge, Rick, Marco Hauptmeier, and Sukanya Sengupta. 2011. Beyond the enterprise: Broadening the horizons of International HRM. Human Relations 64(4): 483-505.

Edwards, Paul, and Jacques Bélanger. 2009. The multinational firm as a contested terrain. In Simon Collinson and Glenn Morgan (Eds.), Images of the Multinational Firm, pp. 193-216. Oxford: Wiley.

Edwards, Tony, Trevor Colling, and Anthony Ferner. 2007. Conceptual approaches to the transfer of employment practices in multinational companies: An integrated approach. Human Resource Management Journal 17(3): 201-17.

Eisenhardt, Kathleen M. 1989. Building theories from case study research. Academy of Management Review 14(4): 532-50.

Errasti, Anjel. 2015. Mondragon's Chinese subsidiaries: Coopitalist multinationals in practice. Economic and Industrial Democracy 36(3): 479-99.

Errasti, Anjel, Ignacio Bretos, and Aitziber Nunez. 2017. The viability of cooperatives: The fall of the Mondragon cooperative Fagor. Review of Radical Political Economics 49(2): 181-97.

Farrell, Diana. 2005. Offshoring: Value creation through economic change. Journal of Management Studies 42(3): 675-83.

Feenstra, Robert C. 2010. Offshoring in the Global Economy. Cambridge, MA: MIT Press.

Ferner, Anthony, and Matthias Varul. 2000. "Vanguard" subsidiaries and the diffusion of new practices: A case study of German multinationals. British Journal of Industrial Relations 38(1): 115-40.

Ferner, Anthony, Tony Edwards, and Anne Tempel. 2012. Power, institutions and the crossnational transfer of employment practices in multinationals. Human Relations 65(2): $163-87$.

Ferner, Anthony, Jacques Bélanger, Olga Tregaskis, Michael Morley, and Javier Quintanilla. 2013. U.S. multinationals and the control of subsidiary employment policies. ILR Review 66(3): 645-62.

Flecha, Ramón, and Pun Ngai. 2014. The challenge for Mondragon: Searching for the cooperative values in times of internationalization. Organization 21(5): 666-82.

Gamble, Jos. 2003. Transferring human resource practices from the United Kingdom to China: The limits and potential convergence. International Journal of Human Resource Management 14(3): 369-87.

Geary, John, and Roberta Aguzzoli. 2016. Miners, politics and institutional caryatids: Accounting for the transfer of HRM practices in the Brazilian multinational enterprise. Journal of International Business Studies 47(8): 968-96.

Goyer, Michel, and Bob Hancké. 2005. Labour in French corporate governance: The missing link. In Howard Gospel and Andrew Pendleton (Eds.), Corporate Governance and Labour Management, pp. 173-96. Oxford: Oxford University Press. 
Harrison, Ann E., Margaret S. McMillan, and Clair Null. 2007. U.S. multinational activity abroad and U.S. jobs: substitutes or complements? Industrial Relations 46(2): 347-65.

Heras, Iñaki. 2014. The ties that bind? Exploring the basic principles of worker-owned organizations in practice. Organization 21(5): 645-65.

Hurt, Marcus J., and Stephanie Hurt. 2005. Transfer of managerial practices by French food retailers to operations in Poland. Academy of Management Executive 19(2): 36-49.

ICA. 2016. World Co-operative Monitor 2016. Brussels: International Co-operative Alliance.

Jensen, Peter D., Marcus M. Larsen, and Torben Pedersen. 2013. The organizational design of offshoring: Taking stock and moving forward. Journal of International Management 19(4): $315-23$.

Kasmir, Sharryn. 2016. The Mondragon cooperatives and global capitalism: A critical analysis. New Labor Forum 25(1): 52-59.

Kedia, Ben L., and Debmalya Mukherjee. 2009. Understanding offshoring: A research framework based on disintegration, location and externalization advantages. Journal of World Business 44(3): 250-61.

Kostova, Tatiana. 1999. Transnational transfer of strategic organizational practices: A contextual perspective. Academy of Management Review 24(2): 308-24.

Lee, Seung-Hyun, and Mona Makhija. 2009. Flexibility in internationalization: Is it valuable during an economic crisis? Strategic Management Journal 30(5): 537-55.

Leca, Bernard, Jean-Pascal Gond, and Luciano B. Cruz. 2014. Building "critical performativity engines" for deprived communities: The construction of popular cooperative incubators in Brazil. Organization 21(5): 683-712.

Lemaître, Andreia. 2013. Popular cooperatives and local development in south-east Brazil: Towards socio-economic pluralism. In Isabelle Hillenkamp, Frédéric Lapeyre, and Andreia Lemaître (Eds.), Securing Livelihoods, pp. 25-46. Oxford: Oxford University Press.

Lertxundi, Aitziber. 2011. Characteristics of human resource management in Basque cooperatives and their response to new international contexts. In Baleren Bakaikoa and Eneka Albizu (Eds.), Basque Cooperativism, pp. 169-211. Reno: Center for Basque Studies.

Luzarraga, Jose M. 2008. Mondragon multi-localisation strategy: Innovating a human centred globalisation. Doctoral dissertation, Mondragon University.

Luzarraga, Jose M., and Iñazio Irizar. 2012. La estrategia de multilocalización internacional de la corporación Mondragón. Ekonomiaz 79: 114-45.

MacLeod, Greg, and Darryl Reed. 2009. Mondragon's response to the challenges of globalization. In Darryl Reed and John J. McMurtry (Eds.), Co-operatives in a Global Economy, pp. 111-40. Newcastle: Cambridge Scholars Publishing.

McMurtry, John J., and Darryl Reed. 2009. Co-operatives in a Global Economy. Newcastle: Cambridge Scholars Publishing.

Meardi, Guglielmo, Paul Marginson, Michael Fichter, Marcin Frybes, Miroslav Stanojević, and András Tóth. 2009. Varieties of multinationals: Adapting employment practices in Central Eastern Europe. Industrial Relations 48(3): 489-511.

Mellahi, Kamel, Jedrzej G. Frynas, and David G. Collings. 2016. Performance management practices within emerging market multinational enterprises: The case of Brazilian multinationals. International Journal of Human Resource Management 27 (8): 876-905.

Mondragon. 2017. 2016 Annual Report. Eskoriatza: Mondragon Corporation.

Oldenski, Lindsay. 2014. Offshoring and the polarization of the U.S. labor market. ILR Review 67(3): 734-61.

Patton, Michael. 2002. Qualitative Research E Evaluation Methods. Thousand Oaks, CA: Sage.

Quintanilla, Javier, Lourdes Susaeta, and Rocío Sánchez-Mangas. 2008. The diffusion of employment practices in multinationals: "Americanness" within US MNCs in Spain? Journal of Industrial Relations 50(5): 680-96.

Roberts, Joanne, and Christoph Dörrenbächer. 2016. Renewing the call for critical perspectives on international business: Towards a second decade of challenging the orthodox. Critical Perspectives on International Business 12(1): 2-21.

Schröder, Martin. 2013. Should I stay or should I go? How moral arguments influence decisions about offshoring production. Economic and Industrial Democracy 34(2): 187-204. 
Taylor, Sully, Schon Beechler, and Nancy Napier. 1996. Toward an integrative model of strategic international human resource management. Academy of Management Review 21(4): $959-85$.

Whyte, William F., and Kathleen K. Whyte. 1991. Making Mondragon. Ithaca, NY: ILR Press.

Wilkinson, Barry, Jos Gamble, John Humphrey, Jonathan Morris, and Doug Anthony. 2001. The new international division of labour in Asian electronics: Work organization and human resources in Japan and Malaysia. Journal of Management Studies 38(5): 675-95.

Yin, Robert K. 2013. Case Study Research, 5th edition. London: Sage.

Zanfei, Antonello. 2012. Playing around an oxymoron: International business with a human face. Critical Perspectives on International Business 8(1): 56-73. 